\title{
Explaining the Type of Audience Attitude toward the Content of Religious Medium (Islamic Republic of Iran Broadcasting) (Case Study)
}

\author{
Prof. Dr. Taher Roshandel Arbatani \\ Associate professor, Department of Media Management, Faculty of Management \\ University of Tehran, Tehran, Iran
}

Somayeh Labafi (Corresponding author)

PhD student of Media Management, Department of Media Management

Faculty of Management, University of Tehran, Tehran, Iran

Email: s_labafi@ut.ac.ir

Doi:10.5296/ jsr.v6i1.7506 URL: http://dx.doi.org/10.5296/ jsr.v6i1.7506

\begin{abstract}
This article is written to theoretically and empirically explain analytical model. In the model, audience attitude toward the content of religious medium (IRIB) is defined as internal variable and the aspects of audience religiosity, his religious knowledge, and type of religiosity as external variables. Each of the variables formulated in research model has theoretical bases. Research method is survey. Data was collected using a handmade questionnaire which was reliable and valid based on test. The statistical population of the study consisted of Isfahan people $(n=300)$. They were randomly sampled. In this study, the effect of aspects of audience religiosity, type of his religiosity and religious knowledge on his attitude toward the content of religious medium is examined in terms of several hypotheses. The analytical model of the study is designed using AMOS. Model fit indices show that Chi square index indicates numerical value of 3.28. Based on what Schumacher and Lomax (2009) suggest as acceptable (i.e. if it is between 1 and 5), it is a good value. In addition to the above index, other indices are also computed for respective model. One of them is Root Mean Square Error of Estimation (RMSEA). It is obtained 0.078 (i.e. <0.08).
\end{abstract}

Keywords: Islamic Republic of Iran Broadcasting, Medium, Religion, Religious Medium 


\section{Introduction and Statement of the Problem}

Religion is a set of beliefs, ethics, rules, and regulations for managing human society and nurturing humans (Javadi Amoli, 1993, p93). On the other hand, religion refers to a special way of living in the world both providing prudence of material life and agreeing with afterworld perfection and eternal real life near the sublime God. It accounts for all aspects of human's need (Tabatabaii, 1985, p130). Accordingly, religion must be publicized for people to enter into it and get familiar with it. A mass media function also is to broadcast the message and submit it to various classes of people.

In the contemporary world, due to the advent of modern communication technologies, mass media forms the main part of human communication (Slavko, 2009, p65). New media is considered to be a powerful medium in transferring information. Hence, it has obtained the power of transferring and interpreting cultures. Media have almost affected all components of human's life in a variety of ways (Mc Kavil, 2003, p78). In defining medium, most references introduce it as a tool and means of mass communication. Yet, we mean that type of technology sending a message to a wide spectrum of audience in various zones and countries. Medium is interpreted as the same mass media (Laughey, 2007, p1).

Regarding the type of historical interaction between religion and medium, numerous studies done regarding religious media examine various theories in two views: the conflict between religion and medium or the interaction between religion and medium. In the former, essentialsitic theories are regarded in philosophical and cultural terms. Yet, in the latter, functionalistic, instrumentalistic, culturalistic theories are considered. Some also take the difference between medium religion and religious medium. Then, they explain the aspects of religious medium. The category religious medium is a new phenomenon and still needed to be descriptively studies to known what and how of its essence. Despite studies done in theoretical area, questions still remain to be answered by extensive research. In this study, researcher have made attempt to examine one of the issues of this field; that is, measuring the type of audience attitude toward the content of religious medium. It is noteworthy that, here, researcher mean Islamic Republic of Iran Broadcasting (IRIB) by religious medium.

Based on the abovementioned, the authors of the article consider national medium as a religious medium which must practice based on its religious principles in all its functions (news, instructional, and ...). Yet, all media including the religious medium (IRIB) have sometimes acted improperly to achieve their upstream objectives. Hence, one of the objectives of this article is to examine the effect of the not so much desirable performance on its diverse content (series, news, kids programs, and commercials) broadcasted from the view of audience.

In this study, the effect of audience religiosity aspects (belief aspect, consequential aspects, emotional aspect, and ritual aspect) on his attitude toward the religiosity of the content of the religious medium is examined. The effect of the type of audience religiosity (secular religiosity, divine religiosity, public religiosity, and pluralistic religiosity) on his attitude toward the religiousness of the content of the religious medium (series, news, kids program, and commercials) is also studied. In the end, researchers have also explored the effect of 
audience religious knowledge (low, medium, much, and too much religious knowledge) on his attitude toward the religiosity of the content of the religious medium (series, news, kids program, and commercials).

\section{Literature Review}

So far, various studies have considered the relationship between religion and medium through several views. In the recent years, extensive attempts and studies have been carried out in the field of religion and medium. In his article, Husseini (2007) has discussed a variety of approaches and theories concerning the nature of medium in three parts including functionalistic, essentialistic, and interactionistic. Musapour and Dortaj (2008) "evaluated IRIB religious animations". Bahonar (2008) has studied "mass media and religious productions or kids" through presenting a communicative-cultural approach in 2006. Hasankhani (2008) has explored "the interaction and conflict between medium and religion in the Middle East with an emphasis on Iran". Mohsenian Rad (2006) has investigated "the promotion of religions via emotional stimulation in contemporary media versus thinking-based promotion in early Islam". Givian (2006) has examined "rite, ritualizing and popular religious culture: a reflection on some of the visual representations of religion and new methods of eulogizing". Newman (1996) has threatened "religion by TV programs regarding traditional beliefs, values, and attitudes". He has examined the competition between TV and religion cultural forces in an extensive theoretical look. Gaudi (2010) conducted a study as "the power of religious media: using religious IRIB and the role of religious organizations in public".

Posing the question “is seeing the same believing?", Gonter and Rachil (1994) examined religion and TV in 1990s. Fore (1987) studied TV, religion, and the formation of faith, values, and culture. Among scholars who have considered the relationship between religion and medium and in general religious medium from different views in their works include Horsfild (1984) in "an American experience of religious TV", Iskil and James (1994) in "a show of religion and spirituality on TV fictional network", Jeffrey (2011) in "TV religious programs", and Daniel (2002) in "religious broadcasting models" (Ravdrad, 2009).

All of these studies have examined the religious content of media and basically the relationship between religion and medium at a macro level, in one way or another. In none, the effect of the type of religiosity and the aspects of audience religiosity on the religiosity of the content of religious medium was studied. Based on the reviews of related literature, audience attitude toward the content of the religious medium is influenced by the type of audience religiosity, type of the aspects of religiosity, and the level of his religious knowledge. Due to the novelty of the subject and the effect of the results of the study on the content of the religious medium (i.e. IRIB) as well as the ignorance of the subject by previous researchers, we examined this issue.

\section{Theoretical Framework}

To build the theoretical framework of the study, first, the existing theories regarding the religious medium under study were reviewed and scrutinized. Then, theories concerning 


\section{Al Macrothink}

research hypotheses and the convergence between them were unfolded.

1) Theories on the Interaction between Religion and Medium

The set of views presented regarding the nature of media and the type of their interaction with religious content can be summarized in terms of three theories. The way each approaches respective religious message and content is explained below:

Instrumental Theories: Technology is neutral and meaningless, per se. Value of technical products is subjected to the extent which it serves human's objectives and goals (Clifford J Christians, 2006, p65).

Essentialistic Theory: The relationship between technology and human blended in his existential structure rather than an external relationship (Binderkrantz, 2012). Properties of technology can only be understood by means of its agreement and adaptation with human being. From this view, technology including medium is a special form of a set of facilities provided to create contemporary techniques.

Contingency Theory: Like any other technological artifact, medium has special contingencies, capacities, facilities, and limitations. Accurately studying and knowing them, it will be possible to optimally exploit medium in transferring religion message (Salimi, 2007, p65).

Reviewing various definitions regarding religious medium, researchers concluded that religious medium comprises the following concepts from the view of researchers of the field: medium has theme and content adopted from religious resources (Sigel, 2000); medium has a religious shape and structure (Schneider, 2004); the content of the medium is adopted from religious resources (Husseini, 2007); the objectives and destinations of medium are not only in parallel with the objectives of religion but also basically follow them (Asad, 1999); religious medium has an effective role in publicizing and promoting religion (Marati, 2001); religious medium reflects the culture and customs accepted by the group of the faithful (Derida, 1995); and, in the widest level, it is also possible to consider the media dependent on religious organizations and centers as religious medium (Graham, 1998). 


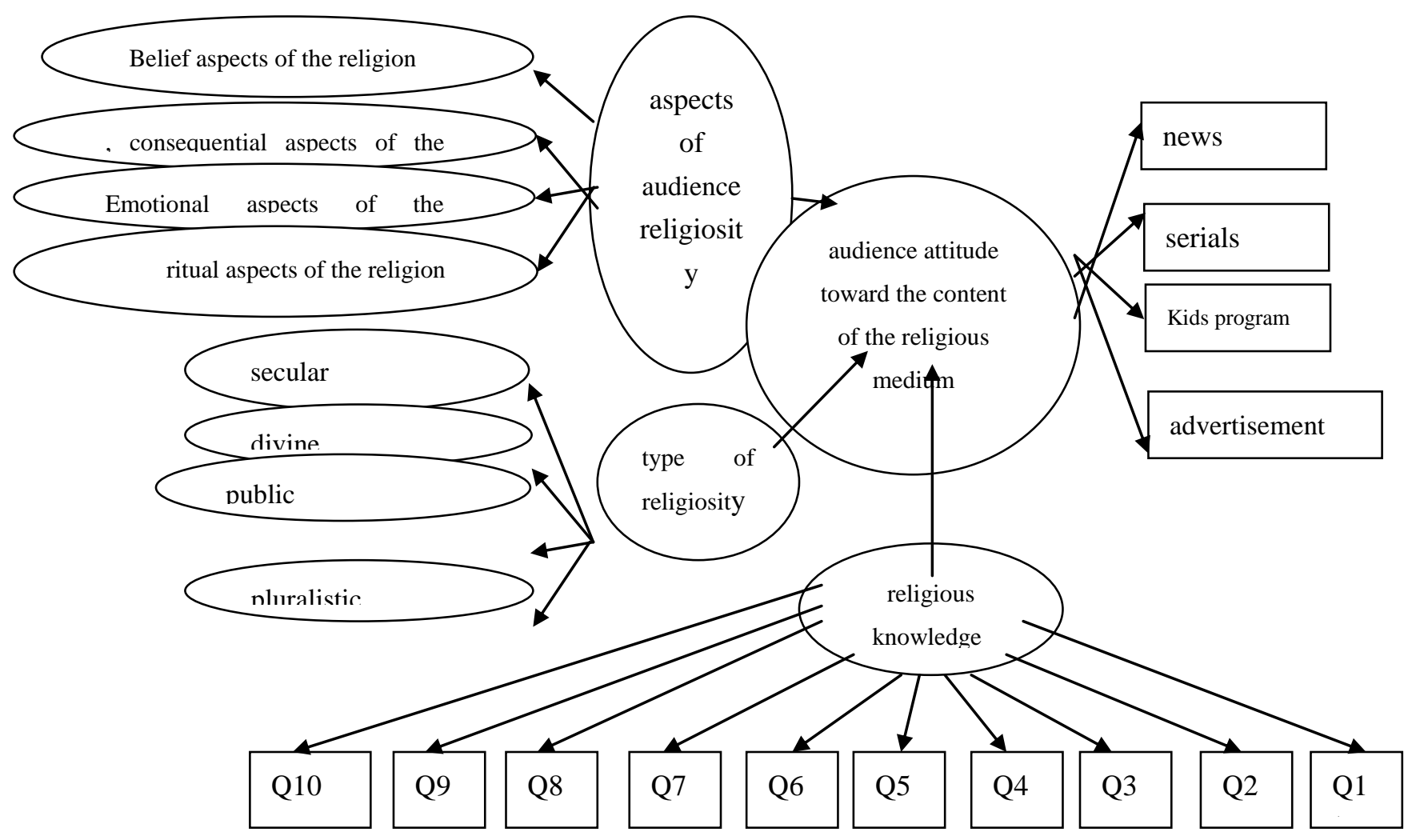

Figure1-conceptual model of research

The theoretical model of the study is illustrated in the following figure. This conceptual model is built based on the items of the questionnaire.

In the model, audience attitude toward the content of the religious medium is taken as dependent or internal variable. The aspects of audience religiosity, his religious knowledge, and type of religiosity are considered as independent or external variables. In this model, the aspects of audience religiosity are explained in terms of four belief, consequential, emotional, and ritual aspects of the religion. Audience is regarded to have four types of religiosity including divine, secular, pluralistic, and popular religiosity. They are adopted from the literature. In addition, four types of contents are considered for religious medium including news, series, kids programs, and commercials.

\section{Research Hypotheses}

As said, research hypotheses were posed based on the accurate review of theories presented in previous studies and their convergence. They were presented based on the emphasis on the relationship between audience attitude toward the content of the religious medium and the 
aspects of his religiosity, religious knowledge, and type of religiosity.

Hypotheses

H1: Audience religiosity aspects affect their attitude toward the content of religious medium.

$\mathrm{H} 2$ : The type of audience religiosity affects their attitude toward the content of religious medium.

H3: The amount of people's religious knowledge affects their attitudes toward religious medium.

\section{Research Method}

It was a survey-based research. Regarding time criterion, it was a cross-sectional study. Regarding depth criterion, it was a prospective study. Analysis unit is an individual and the analysis level is micro. The statistical population of the study consisted of all people in Isfahan. Sample volume was computed using Cochran formula for confidence level of 0.095. Maximum dispersion was estimated 300 people. The sample was carried out randomly.

In this study, we explained the effect of the aspects of audience religiosity, type of religiosity, and religious knowledge on his attitude toward the religious medium using structural equation tests. To obtain the relationship between the components of the theoretical model of the study, a developed methodology known as Structural Equation Modeling (SEM) was applied. It is known as the technique of analyzing latent variables or causal modeling (Ghasemi, 2010, p116).

\section{Course and Site of the Study}

The site of the study was Isfahan. This research was carried out in the interval between winter 2013 and summer 2013.

\section{Results}

Descriptive Results

In this study, over $\% 53$ of respondents were men and \%44 women. Maximum number of respondents was between 24 and 32. Maximum number of respondents was diploma.

Reviewing Independent and Dependent Variables Data

In this study, independent variable includes religiosity aspects, religious knowledge, and variety of religiosity. Its effect on the dependent variable (i.e. audience attitude toward the content of religious medium) was examined. To execute statistical methods and compute suitable test statistic and logically infer about the hypotheses of the study, first, appropriate statistical method must be selected. To do so, knowing about data distribution is of prime significance. In the same respect, accredited test Kolmogorov-Smirnov (K-S) test was used for examining data normality hypothesis. 


\section{Macrothink}

H0: Data distribution is normal.

H1: Data distribution is not normal.

Based on the results of K-S test, it can be concluded that since p-value>0.05 for all independent and dependent variables, all variables of the study have normal distribution. An example of K-S test results for four variables under study is given in the following table. This test was carried out for all variables. Yet, to avoid prolongation of the word, we do not present these tables.

\begin{tabular}{|c|c|c|c|c|c|}
\hline \multicolumn{2}{|l|}{ variables } & $\begin{array}{l}\text { Audience } \\
\text { religiosity aspects }\end{array}$ & $\begin{array}{l}\text { people's } \\
\text { religious } \\
\text { knowledge }\end{array}$ & $\begin{array}{l}\text { type of audience } \\
\text { religiosity }\end{array}$ & $\begin{array}{l}\text { Religious } \\
\text { Medium }\end{array}$ \\
\hline \multicolumn{2}{|l|}{ sample } & 250 & 250 & 250 & 250 \\
\hline \multirow{2}{*}{$\begin{array}{l}\text { Parameter } \\
s \text { of the } \\
\text { normal } \\
\text { distributio } \\
n\end{array}$} & mean & 1.63 & 2.72 & 2.29 & 3.07 \\
\hline & $\begin{array}{l}\text { Standard } \\
\text { deviatio } \\
\mathrm{n}\end{array}$ & 0.84 & 1.29 & 1.28 & 1.34 \\
\hline \multicolumn{2}{|c|}{$\begin{array}{l}\text { Kolmogorov-Smirnov } \\
\text { test statistic }\end{array}$} & 1.754 & 2.723 & 2.625 & 5.747 \\
\hline \multicolumn{2}{|c|}{$\begin{array}{l}\text { Obtained from the test } \\
\text { surface }\end{array}$} & .4 & .351 & .461 & .375 \\
\hline
\end{tabular}




\section{I Macrothink}

\section{Inferential Results}

Table 2: Bivariate Data Analysis

\begin{tabular}{|c|c|c|c|c|c|}
\hline $\begin{array}{l}\text { Hyp } \\
\text { othe } \\
\text { sis }\end{array}$ & $\begin{array}{l}\text { Corre } \\
\text { lation } \\
\text { coeffi } \\
\text { cient }\end{array}$ & $\begin{array}{l}\text { Signif } \\
\text { icant } \\
\text { level } \\
\text { test }\end{array}$ & $\begin{array}{l}\text { ER } \\
\text { RO } \\
\text { R }\end{array}$ & $\begin{array}{l}\text { dependent variable: audience attitude toward the } \\
\text { content of the religious medium }\end{array}$ & $\begin{array}{l}\overrightarrow{0} \\
\overrightarrow{0} \\
\overrightarrow{0} \\
\overrightarrow{0} \\
\frac{0}{0}\end{array}$ \\
\hline \multirow[t]{4}{*}{$\mathrm{H}_{1}$} & 0.39 & 0.002 & 0.05 & the religiosity of the content of news & \multirow{4}{*}{$\begin{array}{l}. \\
0 \\
0 \\
.0 \\
0 \\
0 \\
0 \\
0 \\
0 \\
0 \\
0\end{array}$} \\
\hline & 0.67 & 0.020 & 0.05 & the religiosity of the content of serials & \\
\hline & 0.35 & 0.025 & 0.05 & the religiosity of the content of program kids & \\
\hline & $\mathbf{0 , 3 4}$ & 0.003 & 0.05 & the religiosity of the content of ads & \\
\hline \multirow[t]{4}{*}{$\mathrm{H}_{1}$} & 0.19 & $\mathbf{0 . 0 2 3}$ & 0.05 & the religiosity of the content of news & \multirow{4}{*}{ 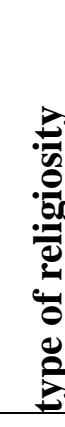 } \\
\hline & 0.32 & 0.002 & 0.05 & the religiosity of the content of serials & \\
\hline & 0.67 & 0.023 & 0.05 & the religiosity of the content of program kids & \\
\hline & 0.82 & 0.000 & 0.05 & the religiosity of the content of ads & \\
\hline \multirow[t]{4}{*}{$\mathrm{H}_{1}$} & 0.85 & 0.000 & 0.05 & the religiosity of the content of news & \multirow{4}{*}{ 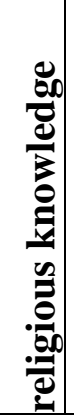 } \\
\hline & 0.56 & 0.003 & 0.05 & the religiosity of the content of serials & \\
\hline & 0.62 & 0.000 & 0.05 & the religiosity of the content of program kids & \\
\hline & 0.69 & 0.002 & 0.05 & the religiosity of the content of ads & \\
\hline
\end{tabular}

\section{Hypotheses Testing Results}

Regarding hypotheses, as in the table, all hypotheses were approved. These effects are significant. Hence, we can generalize results of the sample over the statistical population with confidence level of 0.95 . Accordingly, research hypotheses are approved.

Yet, Ghasemi (2010) has emphasized that although bivariate statistical analyses are considered as the main basis for hypotheses testing and responding research questions, they are never adequate in this regard. Here, multivariate statistical analyses contribute researchers to obtain reality-based results. Hence, in the forthcoming, multivariate statistical methods, 


\section{$\triangle$ Macrothink}

SEM, and measurement methods as well as AMOS are used. Results are showed in Figure (2).

Figure (2) illustrates the measurement model formulated based on theoretical framework and the standard values estimated for all parameters. The formulated model is completely based on theoretical framework and theoretical model designed in previous sections. That is, each of the open parameters defined in the model has theoretical and empirical background. On the other hand, the approach under study is confirmatory approach rather than alternative models approach or exploratory approach.

The model of this study is the second-order factor model playing the role of measurement model. Again, variables and factors observed in the model are simultaneously estimated and tested. All factor loads existing in the model are significant.

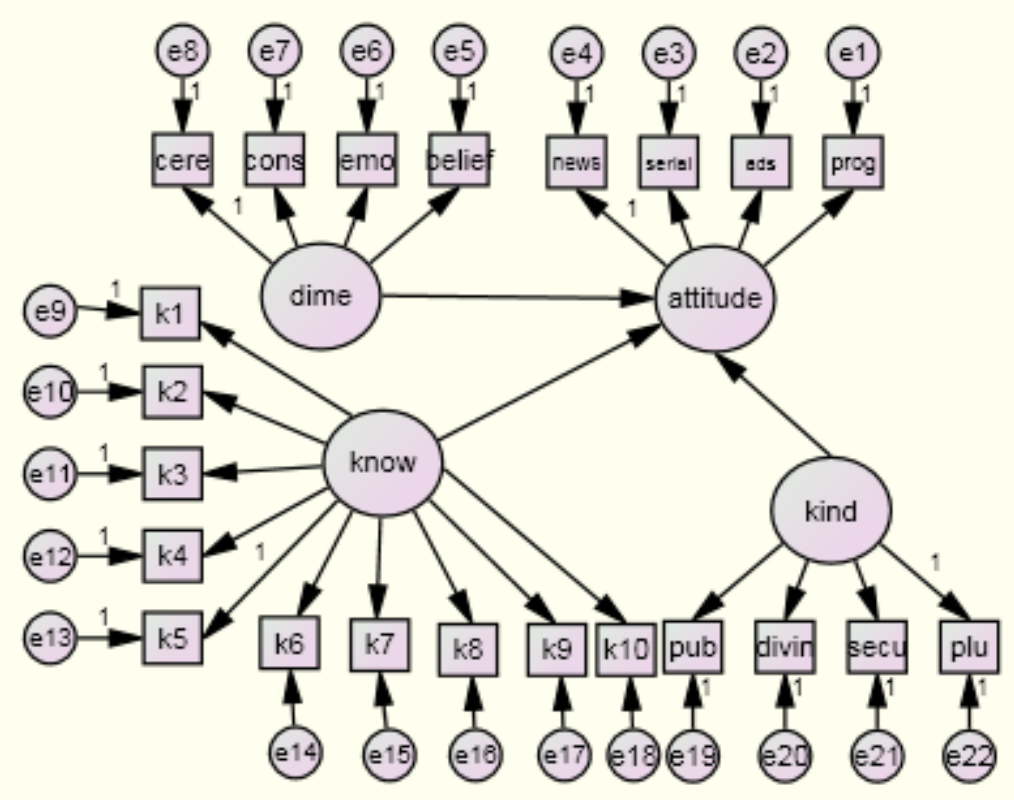

\section{Discussion and Conclusion}

Interpreting Model Goodness of Fit Results

Examining model fit is aimed to determine the extent to which the whole model adopts and agrees with empirical data. There is a wide set of goodness of fit criteria and indices. They can be used for measuring the whole model goodness of fit. None of them is prior to others in all aspects. This is because a special fit index acts differently depending on the sample volume, estimation method, model complexity, and normality hypotheses or a combination of these factors (Ghasemi, 2010, p19). In this section, the conceptual pattern of the study is examined in terms of draw path analysis using various methods of measuring goodness of fit. A complete model of structural equations actually indicates an integration of path diagram and Confirmatory Factor Analysis (CFA). Generally, in working with AMOS, each of the obtained indices for the model does not show the model goodness of fit or its lack of 
goodness of fit on its own. Rather, these indices are needed to be interpreted together (Bayazidi, 2012, p87). Table (6) indicates the main indices of research model goodness of fit. The following table shows that the conceptual pattern of the study is suitable regarding explanation and goodness of fit.

The indices of model goodness of fit show that the model has a good fitting; that is, chi square index indicates the numerical value of 3.28. Regarding what Schumacher and Lomax (2009) propose as acceptable (i.e. between 1 and 5), it is a good value. Furthermore, other indices were also computed for the model. Root Mean Square Error of Approximation (RMSEA) is among them. It was obtained 0.078 (i.e. <0.08). If indices CFI and PCFI are respectively higher than 0.90 and 0.50 , model goodness of fit will be appropriate.

In sum, the indices of the model goodness of fit indicate the acceptability of the model. On the other hand, empirical data collected considerably support the formulated theoretical model. However, about $\% 90$ of the example variance-covariance matrix produced by variance-covariance matrix can be explained based on parameters. It can be expected that a better fit is obtained by removing or adding some paths. Due to the lack of necessary theoretical principles for proposed paths (based on correction indices), it was abandoned. The indices of the model goodness of fit are listed in the following table. Based on the table, it does not seem necessary to correct model to improve the indices of the model goodness of fit.

Table 6: Conceptual model goodness of fit indices

\begin{tabular}{|l|l|}
\hline Goodness of fit index & value \\
\hline Chi square on FD & 3.28 \\
\hline
\end{tabular}

Value of goodness of fit index cmin is 1376.533. The large value of this index approves the model.

Generally, it can be concluded that IRIB audience considers this medium to be religious to a great extent (except in a few aspects presented in the hypotheses). The theoretical model of the study obtained from literature review was confirmed by the indices of goodness of fit. It indicates the effect of each aforementioned aspect on the type of audience attitude toward the content of religious medium and explains audience attitude toward this type of medium explained below.

Based on the results, the effect of the aspects of audience religiosity on his attitude toward the content of religious medium (0.646) is higher than other indicators. Hence, it can be said that religiosity aspects are better indices as compared to other ones. Yet, it must be noted that all latent variables in this study making the latent variable audience attitude toward the content of religious medium generally act at an average level. This is because the desirable standardized regression weight is $>0.7$.

The coefficient of belief aspect is 0.65 , consequential aspect 0.71 , emotional aspect 0.521 , 
and ritual aspect 0.76 . It can be said that ritual aspect index plays a greater role in the type of audience attitude toward the content of religious medium. In general, the people under study care further for religious rites. When IRIB cover religious rites including Ramadan and Moharram rites well, the audience will consider it more religious. Hence, our audience in Isfahan further considers the superficial aspects of religion in medium.

Latent variable pluralistic is 0.054 , latent variable secular religiosity 0.423 , latent variable divine religiosity 0.676 , and latent variable popular religiosity 0.398 . It can be said that index divine religiosity plays a more effective role in audience attitude toward the content of religious medium. Regarding the coefficients (regression weights) and all types of religiosity, most people under study have divine religiosity. Measures of divine religiosity also mentioned in this article (including the fact that they are faithful people who are fiqhi and religious experts; for them, religion and sharia are the bases of religiosity and if, in some cases, there is any conflict between social realities and the view of religious expert, they will act for religion and sharia's good) play a determining role in audience attitude toward religious medium.

Latent variable audience religious knowledge is 0.453 . It can be said that it explains the type of audience attitude toward religious medium as 0.453 . In general, most people believed that the frame of movie in the religious medium claims further about the religiosity. It further agrees with religious principles. That is, for example, a person with low religious knowledge and the one with lower religious knowledge, both have found the content of IRIB programs to be religious. Except that, the divine religiosity aspects are more important to individuals with lower religious knowledge while the aspects of pluralistic religiosity are more important to individuals with higher religious knowledge. In sum, national medium has covered all of these aspects. Regarding the contents broadcasted, the audience has considered commercials as less adapted to religious principles and criticized it. Again, women with high ritual religiosity are dissatisfied with the kids programs and consider it to be less religious as compared to three contents (news, commercials, and series).

\section{Acknowledgement}

we acknowledge of university of Tehran for funded this research .

\section{Corresponding Author:}

Somayeh labafi, phd student of media management, department of media management, faculty of management, university of Tehran, Tehran, Iran

(s_labafi@ut.ac.ir)

\section{References}

1. Aron Raymon (2002), the main stages of thinking in sociology, Trans. by Mohammadbagher Parham, Scientific and Cultural Press 
2. Esmaili Mohsen (2010), the legal status of media mission, Research and Query 35, p25

3. M Hover, Stewart \& Lin Scofield Clark (2003), "the common point of medium, culture, and religion, a bibliographical article”, Stewart M Hover \& Nat Landby, Rethinking Medium, Religion, and Culture, Tehran, Soroosh

4. Thomson Kenneth (2002), religion and secularization, Trans. by Ali Bahrampour, Kavir Press

5. Husseini, Hassan (2007), religion and medium, religious medium or medium religion: theoretical studies", in Mohammadreza Javadi and Hamid Abdollahian, Religion and Medium, Tehran, Radio Research Office

6. Javadi Amoli Abdollah (1993), Religion, Qom, Islamic Press

7. Sevrin \& Tankard (2008), Communication Theories, Trans. by Alireza Dehghan, 3rd print, University of Tehran

8. Salimi Mohammad (2007), culture, medium, and secularized process, set of articles of National Conference on TV and Secularism, p249

9. Sharaf al-Din Sayyid Hussein (2007), religion and medium, 17th year, No. 131, p13

10. Kozer Lewis (2003), sociology pioneers' life and thinking, Trans. by Mohsen Salasi, Scientific Press

11. Ghasemi Vahid, Esfarjani Zahra (2011), the sociological explanation of the effect of religiosity on intergroup social capital (Case Study: Isfahan), Applied Sociology Quarterly, No. 2

12. Ghasemi Vahid (2004), theoretical and empirical analysis regarding religiosity and its criteria, Isfahan Culture Quarterly, No. 29

13. Ravedrad Azam (2009), the role of religious and non-religious TV programs in decreasing or increasing religiosity, Research Quarterly

14. Tabatabaii Mohammad Hussein (1985), Tafsir al-Mizan, Qom, Teachers Society Press

15. Mc Kwail Dennis (2003), an introduction into mass communication theories, Trans. by Parviz Ejlali, 1st print, Media Research and Studies Center

16. Mohsenian Rad Mehdi (2006), promoting religion through emotional stimulation in contemporary media versus thinking-based promotion in early Islam, Iranian Association of Cultural Studies and Communication Quarterly, 2nd year, No. 5, p75

17. Hosfild Peter (1984), religion evolution in media convergence era, Journal of Religion and Culture, p222 